\title{
Tissue engineering in mandibular reconstruction: osteogenesis-inducing scaffolds
}

\author{
Laurel Nelms ${ }^{1}$, William Jack Palmer ${ }^{2}$ \\ 'University of California Riverside School of Medicine, Riverside, CA 92521, USA. \\ ${ }^{2}$ Boston University School of Medicine, Boston, MA 02118, USA.
}

Correspondence to: Laurel Nelms, University of California Riverside School of Medicine, UC Riverside: School of Medicine Education Bldg. 900 University Ave. Riverside, CA 92521, USA. E-mail: Laurel.Nelms@medsch.ucr.edu

How to cite this article: Nelms L, Palmer WJ. Tissue engineering in mandibular reconstruction: osteogenesis-inducing scaffolds. Plast Aesthet Res 2019;6:21. http://dx.doi.org/10.20517/2347-9264.2019.40

Received: 22 Aug 2019 First Decision: 9 Sep 2019 Revised: 12 Sep 2019 Accepted: 18 Sep 2019 Published: 23 Sep 2019

Science Editor: Ali-Farid Safi Copy Editor: Jia-Jia Meng Production Editor: Jing Yu

\begin{abstract}
Currently, the gold standard for aesthetic and functional reconstruction of critical mandibular defects is an autologous fibular flap; however, this carries risk of donor site morbidity, and is not a promising option in patients with depleted donor sites due to previous surgeries. Tissue engineering presents a potential solution in the design of a biomimetic scaffold that must be osteoconductive, osteoinductive, and support osseointegration. These osteogenesis-inducing scaffolds are most successful when they mimic and interact with the surrounding native macroand micro-environment of the mandible. This is accomplished via the regeneration triad: (1) a biomimetic, bioactive osteointegrative scaffold, most likely a resorbable composite of collagen or a synthetic polymer with collagen-like properties combined with beta-tri calcium phosphate that is 3D printed according to defect morphology; (2) growth factor, most frequently bone morphogenic protein 2 (BMP-2); and (3) stem cells, most commonly bone marrow mesenchymal stem cells. Novel techniques for scaffold modification include the use of nano-hydroxyapatite, or combining a vector with a biomaterial to create a gene activated matrix that produces proteins of interest (typically BMP-2) to support osteogenesis. Here, we review the current literature in tissue engineering in order to discuss the success of varying use and combinations of scaffolding materials (i.e., ceramics, biological polymers, and synthetic polymers) with stem cells and growth factors, and will examine their success in vitro and in vivo to induce and guide osteogenesis in mandibular defects.
\end{abstract}

Keywords: Osteogenic scaffolds, mandibular reconstruction, tissue engineering, regeneration triad, bone morphogenic protein, bone marrow mesenchymal stem cells, beta-tri calcium phosphate, gene activated matrix 


\section{INTRODUCTION}

A mandibular defect is the loss of a lower jaw bone segment that produces a gap within the bone of $2 \mathrm{~cm}$ or more, resulting in a continuity or non-continuity mandibular defect ${ }^{[1]}$. These defects primarily arise from tumor resection, infection, physical trauma, and osteomyelitis ${ }^{[2]}$. Such a critical defect will not heal on its own or regenerate more than $10 \%$ of the lost bone within the lifetime of the patient ${ }^{[3]}$. Not only is mandibular bone important for craniofacial aesthetics, but also for the support of muscles of mastication, facial expression and speech $^{[4]}$. Therefore, the choice of scaffold to repair the defect must allow for sufficient muscle attachment to restore oral and maxillofacial function, which has been shown to have significant impact on the patient's quality of life ${ }^{[5]}$. Thus, to achieve successful reconstruction, care must be taken to restore both aesthetics and functional capacity ${ }^{[6]}$.

The autologous fibular free flap is currently the workhorse for mandibular defect repair which, along with other autologous free vascularized tissue transfer, is considered the "gold standard" for mandibular reconstruction because of their osteogenic, osteoinductive, and osteoconductive properties, in combination with the avoidance of an immune reaction ${ }^{[7,8]}$. These grafts also contain live stem or osteoprogenitor cells that themselves migrate, proliferate, and potentiate bone healing ${ }^{[9]}$. The major concern with using a fibular free flap is donor site morbidity, which has been reported to occur in $31.2 \%$ of patients ${ }^{[10]}$. These complications include wound-healing disturbance, paresthesias, cold intolerance, motor weakness of the lower leg muscles, pain, edema, poor aesthetics, and gait disturbance, and has been reported to lead to long term morbidities in $17 \%$ of patients, and severe disability in $4 \%$ of patients ${ }^{[11]}$. To circumvent this problem, cadaver grafts may be an attractive option, however, osteoclastic resorption, risk of disease transmission (viral) and immune reaction make this a less than ideal alternative ${ }^{[12-14]}$. Additionally, synthetic grafts designed from metals or polymers are not bioactive and do not bond to bone or support bone cell function, and can also induce the formation of fibrous tissue at the interface between the implant and bone, which can interfere with bone healing and cause bone resorption, fracture, and eventual failure of the implant ${ }^{[15-17]}$.

If advancement is to be made beyond these methods in an effort to prevent such suffering to the patient, the following factors seem to be important in the design of a biotechnology capable of adequately closing a critical osseous defect: (1) a scaffold to allow bone growth on its surface (osteoconduction); (2) growth factors that induce osteogenesis (osteoinduction); (3) cells that will support osteogenesis; and (4) vascular supply and integration for the delivery of oxygen and nutrients to developing and native tissue ${ }^{[14,18]}$. Of these, vascularization has been a limiting factor for the use of scaffolds in mandibular repair, since both in vitro and in vivo construct implantation lack pre-existing vasculature ${ }^{[19]}$. Because of these multifactorial considerations, tissue engineering might provide the solution to this problem ${ }^{[20]}$.

The critical focus of first-generation biomaterial design was passive biocompatibility; it was not until second-generation biomaterials that biointeractivity for the stimulation of active tissue regeneration emerged $^{[2]}$. Third-generation biomaterials are bioresponsive, e.g., they can activate genes to influence all aspects of proliferation and differentiation of cells ${ }^{[22,23]}$. This assembly of scaffold material, scaffold structure (i.e., pore size), cells and growth factors reveals the multidisciplinary nature of tissue engineering, which is the intersection of material science, mechanical engineering, clinical medicine, and genetics ${ }^{[21]}$. In mandibular reconstruction, the primary goals of tissue engineering include reducing donor site morbidity, operative time, and operative complexity ${ }^{[24]}$. If non-vascularized flaps can be used (i.e., patients who have not been and are not planned to undergo radiation), favorable results have been reported with the adjunct use of tissue engineering for mandibular reconstruction ${ }^{[25,26]}$. Furthermore, modern regenerative medicine builds on tissue engineering designs to direct the surrounding native cellular environment toward a healing process, thereby making use of foreign biological material to recreate cells and rebuild tissues. 
In order to accomplish this, an effective bone scaffold must satisfy the following requirements: osteoconductivity, osteoinductivity and osseointegration ${ }^{[27]}$. Osteoinductivity is the ability of a material to recruit multipotent cells and encourage their differentiation into an osteoblastic lineage ${ }^{[28]}$. This is typically accomplished adding both growth factors and stem cells, such that growth factors signal to surrounding mesenchymal stem cells to differentiate into chondroblasts and osteoblasts to form new bone ${ }^{[29,30]}$. In the context of mandibular reconstruction, stem cells have potential to regenerate oral and dental tissues, such as bone, dentin, cementum, periodontal ligaments, mucosa, and salivary glands ${ }^{[22]}$. Mesenchymal stem cells are the most common source of osteoprogenitor cell used, and may be derived from bone marrow, adipose tissue, and dental and periodontal tissue, and their differentiation is guided by growth factors [such as bone morphogenic protein (BMP)]. Such involvement and interaction between growth factors are essential to the process of native bone healing, including vascular endothelial growth factor (VEGF), fibroblastic growth factors, insulin-like growth factors, platelet-derived growth factor, and BMP, to name a few ${ }^{[31]}$. During osteogenesis, an osteoconductive material will allow the growth of bone not only on the scaffold surface, but also into pores and channels, such that both cortical and cancellous bone are formed around and within the framework ${ }^{[32]}$. Such materials may also be designed to be resorbed in order to encourage growth of native bone. Osseointegration is the degree to which the native bone and the implant favorably interact, and such incorporation of a graft is influenced by many factors, such as the type of bone scaffold used and the site of implantation ${ }^{[33]}$. Thus, the general principle underlying third generation biomaterials is the regeneration triad: (1) an extracellular matrix (ECM) scaffold, which can be made of varying material to create a porous $3 \mathrm{D}$ structure that may be seeded with; (2) growth factors; and (3) stem cells $\mathrm{s}^{[34,35]}$. Ideally, scaffolds should be designed to provide regenerative signals to surrounding cells, while simultaneously improving cell adhesion, proliferation, and differentiation ${ }^{[36]}$, and mechanical rigidity or flexibility ${ }^{[37]}$.

Thus, there is extensive flexibility in assembling a scaffold. The choice of scaffold material itself can be varied, and sometimes may be used successfully on its own or in combination with other materials. Furthermore, modification of the scaffold material by coating its surface with nanoparticles, an ECM molecule (such as collagen), or a growth factor (such as BMP-2) has been shown to improve tissue properties $^{[38]}$. In this review, we will explore the success of varying combinations of the above scaffolding materials, and will examine their success in vivo and in vitro in inducing and guiding osteogenesis in mandibular defects.

\section{SCAFFOLD MATERIALS AND STRUCTURE}

Beyond the biocompatibility of a scaffold, as has been argued by Chocholata et al ${ }^{[21]}$, the most important aspect of scaffold design is its three dimensional structure, namely the degree of pore interconnectivity and pore size, both of which effect the degree of cell attachment and three dimensional regeneration of tissue, as well as cell growth, proliferation, and differentiation, diffusion of waste and the degradation products of scaffolds. The goal of these materials is to initiate or enhance bone formation - if pore size is too small, it can hinder cell migration, and if too large will result in suboptimal binding of cells to the scaffold ${ }^{[18,39]}$. For maximal osteoconductivity, the ideal pore size as described by Ghayor and Weber ${ }^{[40]}$ based on in vivo data is 0.7-1.2 mm, and the size of connections between pores should be between 0.5-1.2 $\mathrm{mm}$; sizes larger than this are detrimental to osteoconductivity. During osteointegration, these porous spaces are initially populated by capillaries, perivascular tissues, and osteoprogenitor cells, followed by incorporation of the porous structure within the newly formed bone ${ }^{[4]]}$. Additionally, the scaffold must be designed to degrade at an appropriate rate so that there is enough time for bone regeneration ${ }^{[42]}$. This is especially relevant in pediatric patients, where the future growth of the mandible must be considered. In this case, fixation of the mandible using titanium locking reconstruction plates does not allow for mandibular growth over time, and might result in facial asymmetry and problems with occlusion as the patient grows ${ }^{[24]}$. Resorbable plates have been developed in order to address this, but their drawbacks include postoperative plate 
fracture and the development of delayed foreign-body reactions, and this potential harm to the patient's well-being might discourage their use; consequently, the focus on "resorbable" material has consequently shifted to "bioabsorbable" scaffolding, which combines biodegradation with osteoconduction ${ }^{[43,44}$. Lastly, the mechanical properties of the material must sufficiently mimic the native tissue at the implantation site in order to support functionality ${ }^{[45]}$. These factors will vary with scaffolding material, and will be described below.

A key requirement of effective tissue engineering is constructing a cellular environment that mimics critical aspects of the in vivo setting through proper control of the materials and mechanical setting as well as the chemical environment. The macroscopic structure of bone consists of a cortical outer layer encasing porous trabecular bone ${ }^{[29]}$. However, it is the nanoscopic structure of bone that yields its mechanical, biological and chemical properties, and this heterogenous structure is importantly irregular and anisotropic ${ }^{[46,47]}$. The ECM of bone is comprised of $60 \%$ mineral [hydroxyapatite (HA)] and 30\% organic matrix ${ }^{[48]}$. The organic components give bone tissue its flexibility, and mainly consist of collagen (type I collagen, type III and type IV collagen), and together with fibrin and over 200 types of noncollagenous matrix proteins (glycoproteins, proteoglycans, sialoproteins, etc.), collagen forms the native scaffold for mineral deposition ${ }^{[15,48]}$. These $\mathrm{HA} \mathrm{Ca}_{3}\left(\mathrm{PO}_{4}\right)_{2} \cdot(\mathrm{OH})_{2}$ nanocrystals, inlayed between individual collagen fibers, give bone its mechanical strength and rigidity ${ }^{[49]}$. Due to this structure, bone tissue can be treated as a ceramic-organic bio-nanocomposite complex ${ }^{[48]}$.

In an effort to design biomimetic material, natural (some authors also called these biological) scaffolds use existing ECM materials, and may be protein-based (e.g., collagen, fibrin) and polysaccharide-based (e.g., chitosan, alginate, glycosaminoglycans, hyaluronic acid $)^{[50-52]}$. Such material also contains cross-linking agents (e.g., glutaraldehyde, water-soluble carbodiimide), which can be adjusted to modify degradation $\operatorname{rates}^{[37]}$. One method to achieve both porosity and biocompatability is to mimic the collagen network of the ECM of bone using nanofibrous scaffolds ${ }^{[53]}$. This can be constructed using electrospun (PLLA) scaffolds, which when coated with HA has been shown to induce calcium deposition and mineralization and the formation of higher order bone structures such as trabeculi and bone marrow, when combined with stem cells $^{[54]}$. It has also been shown that electrospun PLLA can be combined with a porous collagen membrane to guide bone regeneration ${ }^{[5]}$.

Single material scaffolds have shown promise in reconstructing mandibular defects. These materials include: biological polymers (collagen, chitosan), ceramics [beta-tri calcium phosphate ( $\beta$-TCP), calcium HA, biphosphate calcium phosphate (BCP)], and synthetic polymers [polycaprolactone (PCL), PLA, PGA, PLGA $]^{[56]}$. The advantages to ceramics are that they are osteoconductive and biocompatible. Herford et al. ${ }^{[57]}$ generated a ceramic compression resistant osteoconductive matrix that was $15 \%$ HA and $85 \% \beta$-TCP that showed a significantly higher bone density and space maintenance than BMP2 combined with resorbable collagen sponge. However, one of the main concerns in the application of HA bone grafts is poor resorption, and several studies have reported fibrous encapsulation around HA ceramic particles inside alveolar bone ${ }^{[58-60]}$. In a $12 \mathrm{~mm}$ full thickness mandibular defect in a rabbit model using $\beta$-TCP ceramic, Lopez et al. ${ }^{[61]}$ found that new bone accounted for half of the defect site repair at 8 weeks post-scaffold implantation, although no stem cell seeding or BMP signaling was used to direct osteoblast differentiation, instead using the properties of the biomaterial itself to direct endogenous healing mechanisms. Such calcium phosphate ceramics ( $\beta$-TCP and $\mathrm{BCP}$ ) are promising because of their biocompatibility and drug delivery potential, and they have been shown to be osteoconductive with sufficient mechanical strength, and they can be reliably used in 3D printing methodology ${ }^{[62,63]}$. However, calcium phosphate is insufficiently osteoinductive and requires supplementation with growth factors to induce new bone formation ${ }^{[64]}$. These scaffolds do have lower mechanical strength compared to allografts because they are designed to be degradable such that it can be replaced by new bone; however, the extent of new bone formation, lack of 
host-host bridging, and engraftment is similar ${ }^{[65]}$. In preclinical animal studies, autogenous bone precursor cells seeded onto calcium phosphate ceramic scaffolds, pyrolyzed bovine bone, or calcium carbonate has been comparable to autograft bone in mandibular reconstruction in terms of biomechanical testing, bone bridging, and bone ingrowth ${ }^{[64-66]}$.

The second major category is the synthetic polymer (PCL, PLLA, PLA-PEG, PGA, PLGA, PLGA-PEG, etc.). This material is promising because it allows $3 \mathrm{D}$ printing of complex structures that are biodegradable, bioactive, and undergo controlled degradation ${ }^{[6]]}$. However, PCL is not ideal for mandible tissue engineering due to inferior mechanical properties such as a low compressive $\operatorname{strength}^{[68]}$.

The third category of material is the natural polymer (collagen, chitosan, silk fibroin, alginate, gelatin, etc. ${ }^{[60]}$. Although biocompatibility with natural scaffolds is obviously excellent, there remain issues with potential immunogenicity in some cases. Because they do not induce antigen-antibody reactions, decellularized tissue matrices obtained from processing discarded donor tissue is an attractive solution. When bone matrix is demineralized via removal of HA, the remaining bony matrix is comprised mainly of collagen this biocompatible, bioactive biomaterial has the ability to induce bone morphogenesis via BMP signaling, particularly in stem cells, and can be used as a film, gel, or sponge ${ }^{[70,71]}$. Although they have similar osteoinductive and osteoconductive properties as autologous grafts, they lack the corresponding osteogenic properties ${ }^{[7]}$. Additional major downsides are sourcing, processing, immunogenicity, and disease transmission, as well as lack of mechanical strength to withstand the forces exerted by the muscles of mastication $^{[72,32]}$.

In order to address this, Kakabadze et al. ${ }^{[73]}$ reports development of a novel biologically active bone graft using decellularized cancellous bovine femur seeded with human bone marrow mesenchymal stem cells (BMSCs) and growth factors, which was applied clinically to repair a large mandibular defect following primary tumor resection that successfully repaired the defect and showed maintained mandibular bone volume at 5 months post-op. Importantly, like the use of autologous bone, this graft construction requires use of a barrier membrane to prevent fibrous tissue invasion, and decellularized human amnion/chorion membrane was chosen by the authors due to its osseointegrative properties ${ }^{[73]}$.

However, the shortcomings of using a single material in scaffold construction include: poor strength for biologically-derived materials, brittleness for inorganic materials, and poor cell compatibility and insufficient mechanical strength for synthetic polymers ${ }^{[56]}$. Because of this, combining two or more materials to create a composite scaffold has shown improvement in material properties and biocompatibility. Most often, the polymer of choice is type I collagen, which is most often coated on scaffolds made from PCL, $\mathrm{HA}$, and TCP in order to aim to mimic the structure of native bone ${ }^{[38]}$. Additionally, biomimetic Mg$\mathrm{MgHA} /$ collagen-based scaffolds have been shown to greatly improve osteoblast differentiation ${ }^{[74]}$. When choosing between ceramics to add compressive strength, it should be noted that compared to $\beta$-TCP, HA has low absorption kinetics in vivo (1\%-2\% per year at 5 years postimplantation) ${ }^{[75]}$. An HA-collagen or $\beta$-TCP-collagen scaffold can be $3 \mathrm{D}$ printed, and the combination of biocompatibility, compressive strength, and resorption rate in vivo and in vitro allows for bone replacement over time, and the degradation rate of the material can be altered by increasing the macroscopic surface area by decreasing the strut diameter or altering micro/nano porosity ${ }^{[61]}$.

The scaffold surface may also be modified by the addition of nanoparticles. Most commonly, nano-HA is combined with PCL and chitosan scaffolding ${ }^{[38]}$. Nano-HA is of interest because it has been shown to increase the mechanical properties and improve the protein adsorption capacity of the polymer, while also acting as a substrate for cell attachment and migration during bone regeneration ${ }^{[76]}$. Polyamide66 is a synthetic polymer chosen by Cai et al. ${ }^{[77]}$ to combine with HA due to its biocompatibility, high tensile 
strength, and its similarity to collagen in chemical structure and functional groups ${ }^{[8]}$. When combined with BMSCs in a mandibular defect, this scaffold showed greater biocompatibility and osteoconductivity with the surrounding host bone compared with commercial porous polyethylene (MEDPOR) constructs seeded with BMSCs ${ }^{[77]}$.

One of the fundamental hurdles of bone-tissue engineering is vascularization of tissue. Zhu et al. ${ }^{[79]}$ fabricated pre-vascularized tissues using a method derived from rapid $3 \mathrm{D}$ printing, termed microscale continuous optical bioprinting, in which two types of biocompatible and photopolymerizable hydrogelsglycidal methacrylate-HAp and gelatin methacrylate scaffolds - were pre-designed with vascular channels into which endothelial cells and mesenchymal cells were printed, which resulted in the spontaneous formation of a functional endothelial network both in vitro and in vivo.

Graphene and its derivatives, such as graphene oxide and reduced graphene oxide, is also a promising scaffold material because it is not only biocompatible, but also has been shown to regulate cell behavior, help in differentiation, and improve adhesion, growth and proliferation of cells ${ }^{[21]}$. Graphene is built by layering $\mathrm{SP} 2$ bonded carbon atoms with atomic graphite in a honeycomb lattice structure ${ }^{[80]}$. When combined with natural and synthetic biomaterials, graphene has been shown to increase osteogenic potential and mechanical strength of the scaffold ${ }^{[8,81]}$. However, graphene has been shown to be toxic at higher concentrations and is not reliably biodegradable, warranting further investigation before clinical trials $^{[80,81]}$.

\section{STEM CELLS AND GROWTH FACTORS}

Most tissue engineering utilizes living cells, and supplying enough cells is obviously a critically important issue. Cells are typically derived from: (1) donor tissue, which is often in very limited supply; (2) stem or progenitor cells. Stem cells possess two major properties that make them attractive for deriving large cell quantities: (1) their high proliferative capacity; (2) their multipotency, or ability to differentiate into cells of multiple lineages ${ }^{[37]}$. Bone marrow stoma contains progenitor cells with osteogenic potential, which are referred to as bone marrow stromal cells, or BMSCs ${ }^{[82]}$. BMSCs are a major seed cell source for bone tissue engineering due to their well-known capability of self-renewal (which is an outcome of asymmetric division), and differentiation into the osteoblastic lineage in vitro and in vivo ${ }^{[83-85]}$. Scaffolding has been shown to be capable to support ectopic bone formation when seeded with BMSCs in a mouse model, and the repair of large segmental defects ${ }^{[86,87]}$. Moreover, many previous studies have succeeded in repairing bone defects by using BMSCs in animal models as well as in humans ${ }^{[88]}$.

The procedure to extract autologous BMSCs is painful and associated with potential complications, so effort has been made to explore the use of adipose derived stem cells (ADSCs). Although ADSCs have a higher cell yield, the literature suggests they possess an inferior osteogenic capacity compared to BMSCs, so they are not as desirable in mandibular reconstruction ${ }^{[88]}$. Dental pulp stem cells are also of interest due to their ease of access, low donor site morbidity, and ability to differentiate into fibroblasts, nerve cells, endothelial cells, and odontoblasts in order to facilitate creation of new connective tissue ${ }^{[89]}$. Raspini et al ${ }^{[90]}$ showed that dental pulp stem cells combined with bioactive glass scaffold that was treated with osteogenic medium in vitro showed good biocompatibility and osteogenic induction, making it a promising combination for hard tissue regeneration in the cranio-maxillofacial skeleton. However, the comparative efficacy of these cells between laboratory study and patient intervention remains to be seen ${ }^{[91]}$.

When bone is transplanted, it is degraded and replaced through a process termed "creeping substitution", and this degradation process releases calcium phosphates and osteoinductive proteins that amplify bone regeneration $^{[41]}$. BMPs are a member of the transforming growth factor-beta (TGF- $\beta$ ) superfamily that 
induces the formation of bone and cartilage. In order to mimic this endogenous microenvironment, BMPs are often combined with MSCs in order to amplify their bone-forming potential. This use of MSCs with BMPs to repair mandibular bony defects has shown its effectiveness in animal models ${ }^{[72,92]}$. Jiang et al ${ }^{[93]}$ showed that transfection of BMSCs with hBMP-4 enhances their inherent osteogenic capacity in mandibular defect repair. Zhou et al. ${ }^{[94]}$ showed $\mathrm{rhBMP}-2$ combined with prefabricated tissue engineered vascularized bone flaps produced in vivo induced successful reconstruction of the mandibular defect. Chen et al ${ }^{[95]}$ found that loading a demineralized bone matrix with a formulated collagen-targeting BMP-2 induced better bone formation compared to rhBMP-2, and the authors note remarkable osteoinductive properties with homogenous bone formation. Additionally, BMPs may be combined with non-vascularized bone grafts, such as cadaveric fibula or other non-vascularized bone grafts, to stimulate osteogenesis ${ }^{[24]}$. Such a design has shown capability to reconstruct mandibular defects up to $12 \mathrm{~cm}^{[25]}$. It should be noted that BMP is contraindicated in cancer, because it is thought to stimulate cancer growth (shown in vivo) ${ }^{[96]}$.

The importance of scaffold selection when using BMP-2 and BMP-7 has been well documented. The material must allow sustained diffusion of BMPs throughout the environment and provide matrix for in-growth of osteoprogenitor cells and blood vessels, and the properties of scaffolds constructed with BMP and ceramics, synthetic polymers, or biological polymers differ ${ }^{[69]}$. Currently, collagen is the gold standard delivery system for BMPs. Composite scaffolds are also promising for BMP use, such as PLA/ PEG/HAP which is oseoconductive, or a PLGA-collagen hybrid, which has osteoinductive activity and long stimulation effect ${ }^{[97,98]}$. In terms of novel carriers, nanoparticles and microparticles are becoming increasingly popular due to localized and sustained delivery of BMPs, which can be designed with natural polymers, synthetic polymers, or ceramics. Quinlan et al ${ }^{[99]}$ loaded alginate and PLGA MPs with rhBMP-2 in order to incorporate the polymer into porous HAp-collagen scaffold for bone regeneration, which showed new bone formation in a rat model in vivo. Dual-interacting polymeric nanoparticles were prepared by Seo et al.$^{[100]}$ to form nanocomplexes with BMP-2, which resulted in sustained BMP-2 release and significant bone generation.

BMPs combined with biomaterial appears equivalent to autogenous osteogenic tissue. In humans, native human BMPs, xenogeneic BMPs, rhBMP-2, or rhBMP-7 were reported to yield complete mandibular bony defect bridging without simultaneous use of autogenous osteogenic issue in 29 out of 34 patients ${ }^{[85]}$. It has long been thought that bone growth cytokines could be reliably used in lieu of traditional bone grafting ${ }^{[57]}$. While tissue-engineered autogenous osteogenic tissues without application of osteoinductive BMPs has been reported to restore mandibular continuity ( $n=16$ patients), osteoinductive rhBMP-2 loaded onto various scaffolding materials without concomitant transplantation of autogenous osteogenic tissue has also been shown to restore mandibular continuity ${ }^{[4,101-103]}$.

Other growth factors that have been explored for promoting osteogenesis include recombinant human platelet-derived growth factor, TGF-b, fibroblast growth factor, recombinant human growth/differentiation factor-5, VEGF, and insulin-like growth factor ${ }^{[85]}$. However, BMPs remain the most frequently used compared to other growth factors ${ }^{[38]}$. Beside their ability to induce osteogenic differentiation in stem cells, BMPs can accelerate the healing process ${ }^{[104]}$. However, it should be noted that in a calvaria defect model, BMP-2 and VEGFA had similar bone healing capacities, with FGF-2 displaying a significantly higher bone regeneration capacity; however, the healing rate was lower than with BMP-2 and VEGFA ${ }^{[105]}$. BMP-2 and VEGFA also showed increased angiogenic response upon healing ${ }^{[105]}$. It should also be noted that undesirable clinical outcomes with BMPs have been shown, namely extreme bone proliferation (albeit in a calvarial model), ectopic bone formation, radiculitis, and potential stimulation of neoplasms ${ }^{[106-108]}$. Because of this, investigation into $\beta$-TCP ceramic scaffold coated with an adenosine A2 receptor indirect agonist augmented bone growth as effectively as rhBMP-2 in a $3 \mathrm{~mm}$ defect ${ }^{[109]}$. Adenosine A2A receptor signaling appears to be important for osteoclast differentiation both in vitro and in vivo, and has been shown to promote bone regeneration ${ }^{[110]}$. 


\section{GENE THERAPY}

Gene therapy makes use of native nuclear machinery in order to synthesize a protein of interest via the process of transduction, in which a viral vector is typically used ${ }^{[111]}$. In this way, growth factor can be produced in the region of the defect, and has been reported to support mineralized tissue formation ${ }^{[112]}$. Therefore, expression in the host cell lasts longer (weeks to years) compared to pharmaceutical compounds or recombinant protein, which ranges from several hours to days. This allows continuous production of biologically active molecules, thereby mimicking the endogenous physiological healing response in the microenvironment of the defect ${ }^{[13,114]}$. Viral vectors remain preferred to non-viral vectors because they have been rendered replication-incompetent, and non-viral vectors have insufficient transfection efficiencies ${ }^{[115,116]}$.

In order to induce de novo bone formation in the maxillofacial region in vivo, the genes of interest range from soluble growth factors (PDGF, FGFs), morphogens (BMPs), angiogenetic factors (VEGF), intracellular regulators (LIM mineralization protein-1), transcription factors (Runx2) associated with bone and cartilage-related gene expression ${ }^{[117,118]}$. Due to their ability to initiate and sustain the entirety of the bone formation process, BMPs are the preferred candidates for local gene therapy for bone regeneration ${ }^{[119]}$.

Although gene therapy can be administered via systemic or local injection, gene therapy may be delivered with a biomaterial. This combination of a vector and biomaterial is referred to as a gene activated matrix that acts as a scaffold for delivery of the vector to the area of interest ${ }^{[120]}$. This method may be especially attractive in the repair of mandibular defects, in which cells may be removed from the donor site, be genetically modified and implanted onto the scaffold of choice, and re-implanted into the defect ${ }^{[121]}$. Interestingly, BMSCs have been successfully transfected by various vector systems in order to improve their proliferation and differentiation capacities ${ }^{[117]}$. A meta-analysis by Fliefel et al ${ }^{[115]}$ which considered majority animal-model studies found evidence that gene therapy improves bone formation in maxillofacial defects. These results have not yet been confirmed in human subjects; thus, it remains an exciting approach to mandibular defect repair that warrants future research and randomized clinical trials ${ }^{[15]}$.

\section{CONCLUSION}

Tissue engineering for mandibular reconstruction is most successful when it can mimic and interact with the surrounding native macro- and micro-environment in order to induce and support osteogenesis. Based on the current literature, an optimal mandibular scaffold is comprised of three elements: (1) a biomimetic, bioactive osteointegrative scaffold, most likely a resorbable composite of collagen or a synthetic polymer with collagen-like properties with $\beta$-TCP that is $3 \mathrm{D}$ printed according to defect morphology; (2) growth factor, most frequently BMP; and (3) stem cells, most commonly BMSCs. Overall, the use of a tissue engineered scaffold may prevent common complications of mandibular defect repair with fibular free flap, such as donor site morbidity, and may provide an approach for patients with depleted donor sites due to previous surgeries.

\section{DECLARATIONS}

\section{Authors' contributions}

Made substantial contributions to conception and design, analysis, interpretation, and preparation of the review and manuscript: Nelms L

Assisted with manuscript preparation, as well as provided administrative, technical, and material support: Palmer WJ

\section{Availability of data and materials}

Not applicable. 


\section{Financial support and sponsorship}

None.

\section{Conflicts of interest}

Both authors declared that there are no conflicts of interest.

\section{Ethical approval and consent to participate}

Not applicable.

\section{Consent for publication}

Not applicable.

\section{Copyright}

(C) The Author(s) 2019.

\section{REFERENCES}

1. Akinbami BO. Reconstruction of Continuity Defects of the Mandible with Non-vascularized Bone Grafts. Systematic Literature Review. Craniomaxillofac Trauma Reconstr 2016;9:195-205.

2. Rana M, Warraich R, Kokemüller H, Lemound J, Essig H, et al. Reconstruction of mandibular defects - clinical retrospective research over a 10-year period. Head Neck Oncol 2011;3:23.

3. Brierly GI, Tredinnick S, Lynham A, Woodruff MA. Critical sized mandibular defect regeneration in preclinical in vivo models. Curr Molecular Bio Rep 2016;2:83-9.

4. Nuttegg CM, Hidalgo-Bastida AL. Scaffolds for Mandibular Reconstruction. In: Mozafari M, Sefat F, Atala A, editors. Handbook of Tissue Engineering Scaffolds: Volume One. Woodhead Publishing; 2019. pp. 347-68.

5. Murphy C, Kearns G, Sleeman D, Cronin M, Allen P. The clinical relevance of orthognathic surgery on quality of life. Int J Oral Maxillofac Surg 2011;40:926-30.

6. Wong R, Tideman H, Kin L, Merkx M. Biomechanics of mandibular reconstruction: a review. Int J Oral Maxillofac Surg 2010;39:313-9.

7. Zou W, Chen X. Osteogenesis and Ototoxicity of a Novel Preparation of Autogenous Bone Cement. Otolaryngol Head Neck Surg 2014;151:1020-7.

8. Miles BA, Goldstein DP, Gilbert RW, Gullane PJ. Mandible reconstruction. Curr Opin Otolaryngol Head Neck Surg 2010;18:317-22.

9. Pandit N, Pandit I. Autogenous bone grafts in periodontal practice: a literature review. J Int Clin Dent Res Organ 2016;8:27-33.

10. Kumar G, Narayan B. Morbidity at Bone Graft Donor Sites. In: Banaszkiewicz P, Kader D, editors. Classic Papers in Orthopaedics. Springer, London; 2014. pp. 503-5.

11. Momoh AO, Yu P, Skoracki RJ, Liu S, Feng L, et al. A prospective cohort study of fibula free flap donor-site morbidity in 157 consecutive patients. Plast Reconstr Surg 2011;128:714-20.

12. De Long WG Jr, Einhorn TA, Koval K, McKee M, Smith W, et al. Bone grafts and bone graft substitutes in orthopaedic trauma surgery. A critical analysis. J Bone Joint Surg Am 2007;89:649-58.

13. Wang W, Yeung KWK. Bone Grafts and Bone Substitutes for Bone Defect Management. Orthopedic Biomater 2017:495-545.

14. Stevenson S, Horowitz M. The response to bone allografts. J Bone Joint Surg Am 1992;74:939-50.

15. Wu SH, Li Y, Zhang YQ, Li XK, Yuan CF, et al. Porous titanium-6 aluminum-4 vanadium cage has better osseointegration and less micromotion than a poly-ether-ether-ketone cage in sheep vertebral fusion. Artif Organs 2013;37:E191-201.

16. Decking R, Reuter P, Huttner M, Puhl W, Claes LE, et al. Surface composition analysis of failed cementless CoCr-and Ti-base-alloy total hip implants. J Biomed Mater Res B Appl Biomater 2003;64:99-106.

17. Meneghini RM, Daluga A, Soliman M. Mechanical stability of cementless tibial components in normal and osteoporotic bone. J Knee Surg 2011;24:191-6.

18. Vaccaro AR. The role of the osteoconductive scaffold in synthetic bone graft. Orthopedics 2002;25:S571-8.

19. Ikada Y. Challenges in tissue engineering. J R Soc Interface 2006;3:589-601.

20. Wang KH, Inman JC, Hayden RE. Modern concepts in mandibular reconstruction in oral and oropharyngeal cancer. Curr Opin Otolaryngol Head Neck Surg 2011;19:119-24.

21. Chocholata P, Kulda V, Babuska V. Fabrication of scaffolds for bone-tissue regeneration. Materials 2019;12:E568.

22. Rahman S, Nagrath M, Ponnusamy S, Arany P. Nanoscale and macroscale scaffolds with controlled-release polymeric systems for dental craniomaxillofacial tissue engineering. Materials 2018;11:1478.

23. Hench LL, Polak JM. Third-generation biomedical materials. Science 2002;295:1014-7.

24. Kakarala K, Shnayder Y, Tsue TT, Girod DA. Mandibular reconstruction. Oral Oncol 2018;77:111-7.

25. Desai SC, Sclaroff A, Nussenbaum B. Use of recombinant human bone morphogenetic protein 2 for mandible reconstruction. JAMA Facial Plast Surg 2013;15:204-9. 
26. Schlieve T, Hull W, Miloro M, Kolokythas A. Is immediate reconstruction of the mandible with nonvascularized bone graft following resection of benign pathology a viable treatment option? J Oral Maxillofac Surg 2015;73:541-9.

27. Albrektsson T, Johansson C. Osteoinduction, osteoconduction and osseointegration. Eur Spine J 2001;10:S96-101.

28. Melville JC, Tursun R, Green JM, Marx RE. Reconstruction of a post-traumatic maxillary ridge using a radial forearm free flap and immediate tissue engineering (bone morphogenetic protein, bone marrow aspirate concentrate, and cortical-cancellous bone): case report. J Oral Maxillofac Surg 2017;75:438.e1-6.

29. Stevens MM. Biomaterials for bone tissue engineering. Mater Today 2008;11:18-25.

30. Roberts TT, Rosenbaum AJ. Bone grafts, bone substitutes and orthobiologics: the bridge between basic science and clinical advancements in fracture healing. Organogenesis 2012;8:114-24.

31. Devescovi V, Leonardi E, Ciapetti G, Cenni E. Growth factors in bone repair. Chir Organi Mov 2008;92:161-8.

32. Dawson DR, El-Ghannam A, Van Sickels JE, Naung NY. Tissue Engineering: What is New? Dental Clinics 2019;63:433-45.

33. Khan SN, Cammisa Jr FP, Sandhu HS, Diwan AD, Girardi FP, et al. The biology of bone grafting. J Am Acad Orthop Surg 2005;13:77-86.

34. O'brien FJ. Biomaterials \& scaffolds for tissue engineering. Mater Today 2011;14:88-95.

35. Tabatabaei FS, Motamedian SR, Gholipour F, Khosraviani K, Khojasteh A. Craniomaxillofacial Bone Engineering by Scaffolds Loaded with Stem Cells: A Systematic Review. J Den Sch 2012;30:113-30.

36. Dhandayuthapani B, Yoshida Y, Maekawa T, Kumar DS. Polymeric scaffolds in tissue engineering application: a review. Int J Polym Sci 2011; DOI:10.1155/2011/290602.

37. Berthiaume F, Maguire TJ, Yarmush ML. Tissue engineering and regenerative medicine: history, progress, and challenges. Annu Rev Chem Biomol 2011;2:403-30.

38. Motamedian SR, Hosseinpour S, Ahsaie MG, Khojasteh A. Smart scaffolds in bone tissue engineering: A systematic review of literature. World J Stem Cells 2015;7:657-68.

39. Yu J, Xia H, Ni QQ. A three-dimensional porous hydroxyapatite nanocomposite scaffold with shape memory effect for bone tissue engineering. J Mater Sci 2018;53:4734-44.

40. Ghayor C, Weber FE. Osteoconductive microarchitecture of bone substitutes for bone regeneration revisited. Front Physiol $2018 ; 9: 960$.

41. Cornell CN, Lane JM. Current understanding of osteoconduction in bone regeneration. Clin Orthop Relat Res 1998;355:S267-73.

42. Ge Z, Jin Z, Cao T. Manufacture of degradable polymeric scaffolds for bone regeneration. Biomed Mater 2008;3:022001.

43. Stanton DC, Liu F, Yu JW, Mistretta MC. Use of bioresorbable plating systems in paediatric mandible fractures. J Craniomaxillofac Surg 2014;42:1305-9.

44. Park YW. Bioabsorbable osteofixation for orthognathic surgery. Maxillofac Plast Reconstr Surg 2015;37:6.

45. Hutmacher DW. Scaffolds in tissue engineering bone and cartilage.In: Williams DF, editor. The Biomaterials: Silver Jubilee Compendium 2000; pp. 175-89.

46. Wang X, Xu S, Zhou S, Xu W, Leary M, et al. Topological design and additive manufacturing of porous metals for bone scaffolds and orthopaedic implants: A review. Biomaterials 2016;83:127-41.

47. Rho JY, Kuhn-Spearing L, Zioupos P. Mechanical properties and the hierarchical structure of bone. Med Eng Phys 1998;20:92-102.

48. Kattimani VS, Kondaka S, Lingamaneni KP. Hydroxyapatite - Past, present, and future in bone regeneration. Bone Tissue Regenerat Insights 2016;7:BTRI-S36138.

49. Walmsley GG, Ransom RC, Zielins ER, Leavitt T, Flacco JS, et al. Stem cells in bone regeneration. Stem Cell Rev Rep 2016;12:524-9.

50. Baier Leach J, Bivens KA, Patrick Jr CW, Schmidt CE. Photocrosslinked hyaluronic acid hydrogels: natural, biodegradable tissue engineering scaffolds. Biotechnol Bioeng 2003;82:578-89.

51. Chevallay B, Herbage D. Collagen-based biomaterials as 3D scaffold for cell cultures: applications for tissue engineering and gene therapy. Med Biol Eng Comput 2000;38:211-8.

52. Zhang R, Ma PX. Poly ( $\alpha$-hydroxyl acids)/hydroxyapatite porous composites for bone-tissue engineering. I. Preparation and morphology. J Biomed Mater Res 1999;44:446-55.

53. Holzwarth JM, Ma PX. Biomimetic nanofibrous scaffolds for bone tissue engineering. Biomaterials 2011;32:9622-9.

54. Seyedjafari E, Soleimani M, Ghaemi N, Shabani I. Nanohydroxyapatite-coated electrospun poly (1-lactide) nanofibers enhance osteogenic differentiation of stem cells and induce ectopic bone formation. Biomacromolecules 2010;11:3118-25.

55. Cai YZ, Wang LL, Cai HX, Qi YY, Zou XH, et al. Electrospun nanofibrous matrix improves the regeneration of dense cortical bone. J Biomed Mater Res A 2010;95:49-57.

56. Jahan K, Tabrizian M. Composite biopolymers for bone regeneration enhancement in bony defects. Biomater Sci 2015;4: 25-39.

57. Herford AS, Lu M, Buxton AN, Kim J, Henkin J, et al. Recombinant Human Bone Morphogenetic Protein 2 Combined With an Osteoconductive Bulking Agent for Mandibular Continuity Defects in Nonhuman Primates. Journal of Oral and Maxillofacial Surgery 2012;70:703-16.

58. Lindhe J, Cecchinato D, Donati M, Tomasi C, Liljenberg B. Ridge preservation with the use of deproteinized bovine bone mineral. Clin Oral Implants Res 2014;25:786-90.

59. Stavropoulos A, Kostopoulos L, Mardas N, Nyengaard JR, Karring T. Deproteinized bovine bone used as an adjunct to guided bone augmentation: an experimental study in the rat. Clin Implant Dent Relat Res 2001;3:156-65.

60. Piattelli M, Favero GA, Scarano A, Orsini G, Piattelli A. Bone reactions to anorganic bovine bone (Bio-Oss) used in sinus augmentation procedures: a histologic long-term report of 20 cases in humans. Int J Oral Maxillofac Implants 1999;14:835-40.

61. Lopez CD, Diaz-Siso JR, Witek L, Bekisz JM, Cronstein BN, et al. Three dimensionally printed bioactive ceramic scaffold osseoconduction across critical-sized mandibular defects. J Surg Res 2018;223:115-22. 
62. Bose S, Tarafder S. Calcium phosphate ceramic systems in growth factor and drug delivery for bone tissue engineering: a review. Acta Biomater 2012;8:1401-21.

63. Inzana JA, Olvera D, Fuller SM, Kelly JP, Graeve OA, et al. 3D printing of composite calcium phosphate and collagen scaffolds for bone regeneration. Biomaterials 2014;35:4026-34.

64. Yuan J, Zhang WJ, Liu G, Wei M, Qi ZL, et al. Repair of canine mandibular bone defects with bone marrow stromal cells and coral. Tissue Eng Part A 2010;16:1385-94.

65. Nolff MC, Gellrich NC, Hauschild G, Fehr M, Bormann KH, et al. Comparison of two $\beta$-tricalcium phosphate composite grafts used for reconstruction of mandibular critical size bone defects. Vet Comp Orthopaed 2009;22:96-102.

66. Schliephake H, Knebel JW, Aufderheide M, Tauscher M. Use of cultivated osteoprogenitor cells to increase bone formation in segmental mandibular defects: an experimental pilot study in sheep. Int J Oral Maxillofac Surg 2001;30:531-7.

67. Hart LR, Li S, Sturgess C, Wildman R, Jones JR, et al. 3D printing of biocompatible supramolecular polymers and their composites. ACS Appl Mater Inter 2016;8:3115-22.

68. Sheikh Z, Najeeb S, Khurshid Z, Verma V, Rashid H, et al. Biodegradable materials for bone repair and tissue engineering applications. Materials (Basel) 2015;8:5744-94.

69. Begam H, Nandi SK, Kundu B, Chanda A. Strategies for delivering bone morphogenetic protein for bone healing. Mat Sci Eng C 2017;70:856-69.

70. Nakashima M, Reddi AH. The application of bone morphogenetic proteins to dental tissue engineering. Nat Biotechnol 2003;21:1025-32.

71. Gardin C, Ricci S, Ferroni L, Guazzo R, Sbricoli L, et al. Decellularization and Delipidation Protocols of Bovine Bone and Pericardium for Bone Grafting and Guided Bone Regeneration Procedures. PLoS One 2015;10:e0132344.

72. Seeherman H, Wozney JM. Delivery of bone morphogenetic proteins for orthopedic tissue regeneration. Cytokine Growth Factor Rev 2005;16:329-45.

73. Kakabadze A, Mardaleishvili K, Loladze G, Karalashvili L, Chutkerashvili G, et al. Reconstruction of mandibular defects with autogenous bone and decellularized bovine bone grafts with freeze-dried bone marrow stem cell paracrine factors. Oncol Lett 2017;13:1811-8.

74. Scarano, Antonio, Felice Lorusso, Giorgio Staiti, Bruna Sinjari, et al. "Sinus augmentation with biomimetic nanostructured matrix: tomographic, radiological, histological and histomorphometrical results after 6 months in humans.” Front Physiol 2017;8:565.

75. Moore WR, Graves SE, Bain GI. Synthetic bone graft substitutes. ANZ J Surg 2001;71:354-61.

76. Wei G, Ma PX. Structure and properties of nano-hydroxyapatite/polymer composite scaffolds for bone tissue engineering. Biomaterials 2004;25:4749-57.

77. Cai B, Jiang N, Zhang L, Huang J, Wang D, et al. Nano-hydroxyapatite/polyamide66 composite scaffold conducting osteogenesis to repair mandible defect. J Bioact Compat Pol 2019;34:72-82.

78. Xiong Y, Ren C, Zhang B, Yang H, Lang Y, et al. Analyzing the behavior of a porous nano-hydroxyapatite/polyamide 66 (n-HA/PA66) composite for healing of bone defects. Int J Nanomed 2014;9:485-94.

79. Zhu W, Qu X, Zhu J, Ma X, Patel S, et al. Direct 3D bioprinting of prevascularized tissue constructs with complex microarchitecture. Biomaterials 2017;124:106-15.

80. Bai, Renu Geetha, Kasturi Muthoosamy, Sivakumar Manickam, and Ali Hilal-Alnaqbi. "Graphene-based 3D scaffolds in tissue engineering: fabrication, applications, and future scope in liver tissue engineering.” Int J Nanomed 2019;14:5753.

81. Prasadh S, Suresh S, Wong R. Osteogenic potential of graphene in bone tissue engineering scaffolds. Materials 2018;11:1430.

82. Bianco P, Gehron RP. Marrow stromal stem cells. J Clin Invest 2000;105:1663-8.

83. Jaquiéry C, Schaeren S, Farhadi J, Mainil-Varlet P, Kunz C, et al. In vitro osteogenic differentiation and in vivo bone-forming capacity of human isogenic jaw periosteal cells and bone marrow stromal cells. Ann Surg 2005;242:859.

84. Frank O, Heim M, Jakob M, Barbero A, Schäfer D, et al. Real-time quantitative RT-PCR analysis of human bone marrow stromal cells during osteogenic differentiation in vitro. J Cell Biochem 2002;85:737-46.

85. Chanchareonsook N, Junker R, Jongpaiboonkit L, Jansen JA. Tissue-engineered mandibular bone reconstruction for continuity defects: a systematic approach to the literature. Tissue Eng Part B Rev 2013;20:147-62.

86. Martin I, Muraglia A, Campanile G, Cancedda R, Quarto R. Fibroblast growth factor-2 supports ex vivo expansion and maintenance of osteogenic precursors from human bone marrow. Endocrinology 1997;138:4456-62.

87. Quarto R, Mastrogiacomo M, Cancedda R, Kutepov SM, Mukhachev V, et al. Repair of large bone defects with the use of autologous bone marrow stromal cells. N Engl J Med 2001;344:385-6.

88. Liao HT, Chen CT. Osteogenic potential: comparison between bone marrow and adipose-derived mesenchymal stem cells. World J Stem Cells 2014;6:288-95.

89. Bakhtiar H, Mazidi A, Asl SM, Ellini MR, Moshiri A, et al. The role of stem cell therapy in regeneration of dentine-pulp complex: a systematic review. Prog Biomater 2018;7:249-68.

90. Raspini G, Wolff J, Helminen M, Raspini G, Raspini M, et al. Dental stem cells harvested from third molars combined with bioactive glass can induce signs of bone formation in vitro. J Oral Maxillofac Res 2018;9:e2.

91. Spagnuolo G, Codispoti B, Marrelli M, Rengo C, Rengo S, et al. Commitment of oral-derived stem cells in dental and maxillofacial applications. Dent J (Basel) 2018;6:E72.

92. Marukawa E, Asahina I, Oda M, Seto I, Alam MI, et al. Bone regeneration using recombinant human bone morphogenetic protein-2 (rhBMP-2) in alveolar defects of primate mandibles. British J Oral Maxil Surg 2001;39:452-9.

93. Jiang X, Gittens SA, Chang Q, Zhang X, Chen C, et al. The use of tissue-engineered bone with human bone morphogenetic protein-4- 
modified bone-marrow stromal cells in repairing mandibular defects in rabbits. Int J Oral Maxillofac Surg 2006;35:1133-9.

94. Zhou M, Peng X, Mao C, Xu F, Hu M, et al. Primate mandibular reconstruction with prefabricated, vascularized tissue-engineered bone flaps and recombinant human bone morphogenetic protein-2 implanted in situ. Biomaterials 2010;31:4935-43.

95. Chen B, Lin H, Wang J, Zhao Y, Wang B, et al. Homogeneous osteogenesis and bone regeneration by demineralized bone matrix loading with collagen-targeting bone morphogenetic protein-2. Biomaterials 2007;28:1027-35.

96. Kokorina NA, Lewis Jr JS, Zakharkin SO, Krebsbach PH, Nussenbaum B. rhBMP-2 has adverse effects on human oral carcinoma cell lines in vivo. The Laryngoscope 2012;122:95-102.

97. Lee EJ, Kim HE. Accelerated bony defect healing by chitosan/silica hybrid membrane with localized bone morphogenetic protein-2 delivery. Mat Sci Eng C 2016;59:339-45.

98. Lu H, Kawazoe N, Kitajima T, Myoken Y, Tomita M, et al. Spatial immobilization of bone morphogenetic protein-4 in a collagenPLGA hybrid scaffold for enhanced osteoinductivity. Biomaterials 2012;33:6140-6.

99. Quinlan E, López-Noriega A, Thompson E, Kelly HM, Cryan SA, et al. Development of collagen-hydroxyapatite scaffolds incorporating PLGA and alginate microparticles for the controlled delivery of rhBMP-2 for bone tissue engineering. J Control Release 2015;198:71-9.

100. Seo BB, Choi H, Koh JT, Song SC. Sustained BMP-2 delivery and injectable bone regeneration using thermosensitive polymeric nanoparticle hydrogel bearing dual interactions with BMP-2. J Control Release 2015;209:67-76.

101. Herford AS, Boyne PJ, Williams RP. Clinical applications of rhBMP-2 in maxillofacial surgery. J Calif Dent Assoc 2007;35:335-41.

102. Herford AS, Boyne PJ. Reconstruction of mandibular continuity defects with bone morphogenetic protein-2 (rhBMP-2). J Oral Maxil Surg 2008;66:616-24.

103. Cicciù M, Herford AS, Stoffella E, Cervino G, Cicciù D. Protein-signaled guided bone regeneration using titanium mesh and RhBMP2 in oral surgery: a case report involving left mandibular reconstruction after tumor resection. Open Dent J 2012;6:51.

104. Jansen JA, Vehof JW, Ruhe PQ, Kroeze-Deutman H, Kuboki Y, et al. Growth factor-loaded scaffolds for bone engineering. J Control Release 2005;101:127-36.

105. Behr B, Sorkin M, Lehnhardt M, Renda A, Longaker MT, et al. A comparative analysis of the osteogenic effects of BMP-2, FGF-2, and VEGFA in a calvarial defect model. Tissue Eng Part A 2012;18:1079-86.

106. Kinsella CR, Cray JJ, Durham EL, Burrows AM, Vecchione L, et al. Recombinant human bone morphogenetic protein-2-induced craniosynostosis and growth restriction in the immature skeleton. Plast Reconstr Surg 2011;127:1173-81.

107. Carragee EJ, Hurwitz EL, Weiner BK. A critical review of recombinant human bone morphogenetic protein-2 trials in spinal surgery: emerging safety concerns and lessons learned. Spine J 2011;11:471-91.

108. Spiro AS, Timo Beil F, Baranowsky A, Barvencik F, Schilling AF, et al. BMP-7-induced ectopic bone formation and fracture healing is impaired by systemic NSAID application in C57BL/6-mice. J Orthop Res 2010;28:785-91.

109. Mediero A, Wilder T, Perez-Aso M, Cronstein BN. Direct or indirect stimulation of adenosine A2A receptors enhances bone regeneration as well as bone morphogenetic protein-2. FASEB J 2015;29:1577-90.

110. Mediero A, Kara FM, Wilder T, Cronstein BN. Adenosine A2A receptor ligation inhibits osteoclast formation. Am J Pathol 2012;180:775-86.

111. Scheller EL, Villa-Diaz LG, Krebsbach PH. Gene therapy: implications for craniofacial regeneration. J Craniofac Surg 2012;23:333.

112. Rabie AB, Dai J, Xu R. Recombinant AAV-mediated VEGF gene therapy induces mandibular condylar growth. Gene Ther 2007;14:972.

113. Rios HF, Lin Z, Oh B, Park CH, Giannobile WV. Cell-and gene-based therapeutic strategies for periodontal regenerative medicine. J Periodontol 2011;82:1223-37.

114. Chatterjee A, Singh N, Saluja M. Gene therapy in periodontics. J Indian Soc Periodontol 2013;17:156.

115. Fliefel R, Kühnisch J, Ehrenfeld M, Otto S. Gene therapy for bone defects in oral and maxillofacial surgery: a systematic review and meta-analysis of animal studies. Stem Cells Dev 2017;26:215-30.

116. Mali S. Delivery systems for gene therapy. Indian J Hum Genet 2013;19:3-8.

117. Fischer J, Kolk A, Pautke C, Warnke PH, Plank C, et al. Future of local bone regeneration-protein versus gene therapy. J Cranio Maxill Surg 2011;39:54-64.

118. Franceschi RT, Yang S, Rutherford RB, Krebsbach PH, Zhao M, et al. Gene therapy approaches for bone regeneration. Cells Tissues Organs 2004;176:95-108.

119. Luo J, Sun MH, Kang Q, Peng Y, Jiang W, et al. Gene therapy for bone regeneration. Curr Gene Ther 2005;5:167-79.

120. Balmayor ER, van Griensven M. Gene therapy for bone engineering. Front Bioeng Biotechnol 2015;3:9.

121. Tarassoli P, S Khan W, Hughes A, Heidari N. A review of techniques for gene therapy in bone healing. Curr Stem Cell Res Ther 2013;8:201-9. 